\title{
The CSCL Community in its First Decade: Development, Continuity, Connectivity
}

\author{
Andrea Kienle • Martin Wessner
}

Q1 Received: 1 August 2005 / Revised: December 2005 /

Abstract Ten years of international CSCL conferences (1995-2005) provide an occasion to reflect on the formation of the CSCL community. Based on quantitative analysis of conference proceedings, lists of participants and program committee members, and on qualitative study of policies and motives, this paper offers insights into the growth of the CSCL community in its first decade. The analysis focuses on participation at different levels of the community. In particular, focus is on the continuity of active and passive membership, the geographical distribution, and the international connectivity of the community. Contrary to expectations, only a relatively small number of people have participated continuously in the community. Concerning the geographical distribution, we found that the community is increasingly international in conference participation, authors, and program committees. The international connectivity of the community is also increasing, which can be seen in a growing number of citations and co-authorships across different countries. In order to interpret the results of our quantitative study, we conducted a qualitative, e-mail-based survey. In this survey we wanted to elaborate the policy of the conference organization, the reasons for international co-authorships and the motivations for participation in CSCL conferences. We contacted 84 members of different target groups (organizers, members of international coauthorships, and randomly selected participants on different levels of participation). The findings are suggestive for the further development of the CSCL community.

Keywords CSCL community · Community analysis · Citation analysis ·

\section{Introduction}

Since the first workshop in 1989 (Acquafredda di Maratea, Italy; documented in O’Malley, 1995) a growing number of researchers has participated in the Computer- 
Supported Collaborative Learning (CSCL) community. An international conference series focusing on CSCL was started in 1995, and now includes seven past conferences and one planned conference in 2007. Because of the growing interest in the work of this community, the International Journal of Computer-Supported Collaborative Learning (ijCSCL) was founded in 2004 in print and online (www.ijCSCL.org) form. Kluwer (now Springer) publishes a CSCL book series that includes five volumes to date. Networks of CSCL researchers have evolved, a prominent example being the CSCL special interest group that is part of the Kaleidoscope network of excellence, which involves over 380 members from all over Western Europe.

The CSCL community can be defined as a scientific community of practice (Kienle \& Wessner, 2005). The term "Communities of Practice," coined by Lave and Wenger (1991), has been defined as "groups of people who share a concern, a set of problems, or a passion about a topic, and who deepen their knowledge and expertise in this area by interacting on an ongoing basis" (Wenger, McDermott, \& Snyder, 2002, pp. 4). Based on this definition, a scientific community-in general as well as the CSCL community - is a community of practice with members working in a common field of research, but with members distributed across disciplines, organizations, cultures, and geographical regions. For their exchange, the members use a combination of face-to-face meetings and, increasingly, technology-mediated interaction. This results in a heterogeneous group, in which different members have different views on the (CSCL) community and its main players. The community makes use of methods from a variety of disciplines and scientific cultures. Members follow or even combine practices of basic and applied research (Fischer, Bouillon, Mandl, \& Gomez, 2003). For the CSCL community, the development of a common theory that integrates the foundations of the relevant disciplines is an ongoing task (Stahl, 2002b; Puntambekar \& Young, 2003).

At the CSCL conference 2003 in Bergen, Norway, there was a lively discussion about the nature of the CSCL community and the identity of this field, e.g., the relation between CSCL and the Learning Sciences. Triggered by these discussions and-as CSCL researchers-motivated by our own curiosity about the evolution of the field, we decided to provide empirical answers to some of these questions about the nature of the CSCL community. In this paper we present our analysis of the CSCL community over the past ten years in order to provide a basis for joint reflection that could influence the community's further development.

Our main research question is whether the CSCL community is coalescing, with a special focus on its becoming more international. We pose the following research questions:

- Development: How does active and passive membership in the community 74 develop?

- Continuity: Do members stay in the community? Are new people joining the community and becoming active members?

- Connectivity: How do the members of the community connect over regional boundaries? Has the connectivity grown over the years?

In addition to a descriptive answer to these research questions we are interested in the policies and motives of the community members concerning the organization of CSCL conferences, international co-authorships, and participation in the conferences. 
An initial, informal survey among participants and authors of previous CSCL 85 conferences pointed out that the following results were expected for the CSCL 86 community:

1. Authors contribute to conferences on a regular basis.

2. A large percentage of members attend most conferences; in addition there is a sound balance between recurring people and newcomers.

3. The connection over regional boundaries is growing.

This paper tries to provide an objective view on the development and continuity of the CSCL community as well as on the connections in the community. In the following article, we describe the methods and data used in our analysis and the main results concerning our research questions. Then we discuss the results from both the quantitative and qualitative study. Finally, we conclude the paper with implications for the further development of the CSCL community and an outlook on next steps for the community analysis.

\section{Methods and Data}

The analysis of scientific communities often builds on bibliometric and social network approaches. Bibliometric approaches are based on the publications of a community and focus on networks of papers linked by citations. Applicable methods include citation analysis (Garfield, 1979), bibliometric coupling (Kessler, 1963) and co-citation analysis (Small, 1973). Citation analysis looks at the citations in publications and constructs networks between publications. Bibliometric coupling regards two publications as related to the extent that they are both cited together in other publications. Co-citation analysis works the other way; two papers are connected to the extent they cite the same publications. Such analyses have been done for fields such as DNA (Garfield, Sher, \& Torpie, 1964), Hypertext (Chen \& Carr, 1999), or Information Science (White \& McCain, 1998).

Social network approaches (Scott, 1991) to scientific communities are based on the members of a community, and focus on networks of people linked, for example, by co-authorship. They utilize measures such as connectedness, diameter, centralization, and the density of a community. This approach has also been applied to a number of research fields (e.g., recently for the field of CSCW (Horn, Finholt, Birnholtz, Motwani, \& Jayaraman, 2004); see also Newman (2004) for other fields). Social network analysis has also been applied in the CSCL community in order to measure the cohesion in collaborative learning teams (Nurmela, Lehtinen, \& Palonen, 1999; Woodruff, 1999; Cho, Stefanone, \& Gay, 2002; Nurmela, Palonen, Lehtinen, \& Hakkarainen, 2003; Reffay \& Chanier, 2003).

Both approaches, bibliometric as well as social network analysis, are used for a formal quantitative analysis of the publications produced by a group, the relationships among publications, and the relationships between group members. Especially in academic disciplines where the importance of publication and citation are high, coauthorship and references in publications can be seen as an indicator of how well members of a field are connected.

For the quantitative analysis of the CSCL community, we combine several approaches. We perform a citation and co-authorship analysis of the artifacts in CSCL

100

101

102

103

104

105

106

107

108

109

110

111

112

113

114

115

116

117

118

119

120

121

122

123

124

125

126

127

128 
conference proceedings. In addition, we analyze other sources, including the lists of participants and lists of program committee members.

Data for citation and co-authorship analysis was mainly gathered from the proceedings of the seven CSCL conferences in 1995, 1997, 1999, 2001, 2002, 2003 and 2005 (Schnase \& Cunnius, 1995; Hall, Miyake, \& Enyedy, 1997; Hoadley \& Roschelle, 1999; Dillenbourg, Eurelings, \& Hakkarainen, 2001; Stahl, 2002a; Wasson, Ludvigsen, \& Hoppe, 2003a; Wasson Baggetun, Hoppe, \& Ludvigsen, 2003b; Koschmann, Suthers, \& Chan, 2005). Additionally, all program committees (CSCL 1995-2005) and all available lists of participation (CSCL 1999, 2001, 2002, 2003 and 2005) were analyzed. ${ }^{1}$ All together, we included 815 artifacts (e.g., posters, papers), 222 program committee members (PC members; PCM), 1,392 authors, and 1,651 conference participants in our analysis. We regard PC member, author, and conference participant as the three levels of participation in the CSCL community. Altogether they constitute the CSCL community. For all these members of the CSCL community, we recorded the following data:

- Name

- Country and continent (of affiliation). This data enables us to analyze the regional distribution of the community.

- Conference in which she/he participated as member of the program committee, as author, or as conference participant. On the basis of this data we analyzed the continuity of the community and transitions between the different degrees of participation.

Recording and analyzing the data posed several challenges: First, it is important to determine unique name identifiers for all community members, e.g., to treat " $\mathrm{C}$. Hmelo," "Cindy E. Hmelo," and "Cindy Hmelo" as one and not three persons. Also, name changes have to be recognized (such as "Cindy Hmelo" and "Cindy Hmelo-Silver"). In addition, other difficulties included members having changing or multiple affiliations, author information differing between online and printed proceedings, etc. While recording the data, we took change of name, typos, etc. into account if we could detect or knew about them. Also, the lists of participants provided by the conference organizers were not exhaustive as, for example, in most cases conference participants who registered on site were not included in the list.

For the citation and co-authorship analysis (for the period 1995-2003), we recorded, for each author contributing to at least three CSCL conferences, the following data:

- Co-authors. This data was used for the analysis of strong connections between members of the community.

- Referenced authors. This data was used for the analysis of weak connections between members of the community. We limited our scope to those referenced authors who participated in at least one CSCL conference as an author.

\footnotetext{
${ }^{1}$ In order to retrieve lists of participants for the 1995 and 1997 conferences we contacted the organizers as well as authors of these conferences. Unfortunately, none of these kept the lists of participants, so we could not take them into account.
} 
To analyze the data concerning the three research questions we carried out the following steps:

- Development: For each conference we analyzed the absolute number of participants, authors, and PC members. For the authors and PC members we also analyzed the regional distribution. The comparison of the data for each conference enables us to characterize the development of the community.

- Continuity: For each author/PC member and conference we analyzed if she/he participated for the first time, or was a repeat participant. This enables us to show, for each conference, the number of new and recurring members. For each member we evaluate at how many conferences she/he participated. Based on these numbers we assess the continuity of the CSCL community.

- Connections in the community: We take into account those connections between members of the community that can be seen in the artifacts printed in the proceedings. These artifacts yield us weak connection through references, and strong connections through co-authorships. The focus on artifacts is justified because the artifacts represent a major part of what is communicated during the conference and between conferences-as a community memory for its members and as a source of information for new people joining the community. These artifacts are considered highly valuable to the community by the community itself (via the review process) and serve as a basis for communication in the community. As we are interested in the connections within the community, we focus on references to authors inside the community. For co-authorship, we limit our analysis to the more active authors who contributed to three or more conferences (between 1995-2003).

181

182

183

184

185

186

187

188

189

190

191

192

193

In order to interpret the results of our quantitative analysis, we conducted a qualitative study in October and November 2005. In this study we wanted to learn more about:

a) Policies of conference organization. Questions addressed the selection of conference locations, the selection of PC members, the factors that influenced the number of selected papers or posters, and the overall acceptance rate.

b) Development of international co-authorships. Questions addressed reasons for international co-authorship, factors that support and constrict international coauthoring, and whether the number of co-authored papers with people from other countries increases, decreases, or remains unchanged.

c) Reasons for the participation in conferences and possible differences in cultures. Questions addressed the reason for participation, whether co-authors are also participating, the influence of the 9/11 event, the main research field, and discipline.

Some of these questions are grounded in comments of reviewers of an earlier version of this paper. The questions about the policy of conference organization (a) were sent by e-mail to the conference chairs and PC chairs of all seven conferences ( 22 in total). The questions concerning international co-authorships (b) were sent to all authors of the 9 identified intercontinental groups of authors of the CSCL 2005 conference (34 authors). The questions about participation (c) were sent to randomly selected people from different levels of participation in the last three conferences: people who participated only in 2002 ( 2 from Europe (EU), 2 from North America (NA)), only in 2003 (2 EU, 2 NA), and only in 2005 (2 EU, 2 NA); participated in 2002 
and 2003 (3 EU, 3 NA), in 2002 and 2005 (2 EU, 0 NA), and in 2003 and 2005 (2 EU, 2 NA); and those who participated in all three conferences (2 EU, 2 NA). Altogether we contacted 28 participants.

The data of quantitative and qualitative studies is available at http://www.csclcommunity.org.

\section{Results}

Development of the Community

Figure 1 shows, for each conference, the absolute numbers of community members in three groups-(conference) participants, authors, and PC members-as well as the number of artifacts.

The number of PC members seems to stabilize around a value of 50-60. The number of authors and artifacts increase until 2002, and slightly decline afterwards. A similar peak for 2002 can be seen in the number of conference participants. In addition, the 1999 conference had a very high number of participants. At least since 1999 (no participation data is available for the 1995 and 1997 conferences), participation is higher for conferences in North America (1999 and 2002) than participation in Europe (2001 and 2003) and Asia (2005).

Concerning the regional distribution of community members for each conference, we focus on authors and PC members as active members of the community. We evaluate the regional distribution on a continent level. In Fig. 2 we see the regional distribution of PC members for all past CSCL conferences. This distribution seems to reflect the respective conference location: Asian involvement is highest for the conference in Asia (2005), European involvement for the conferences in Europe (2001 and 2003) and North American involvement is highest for conferences in North

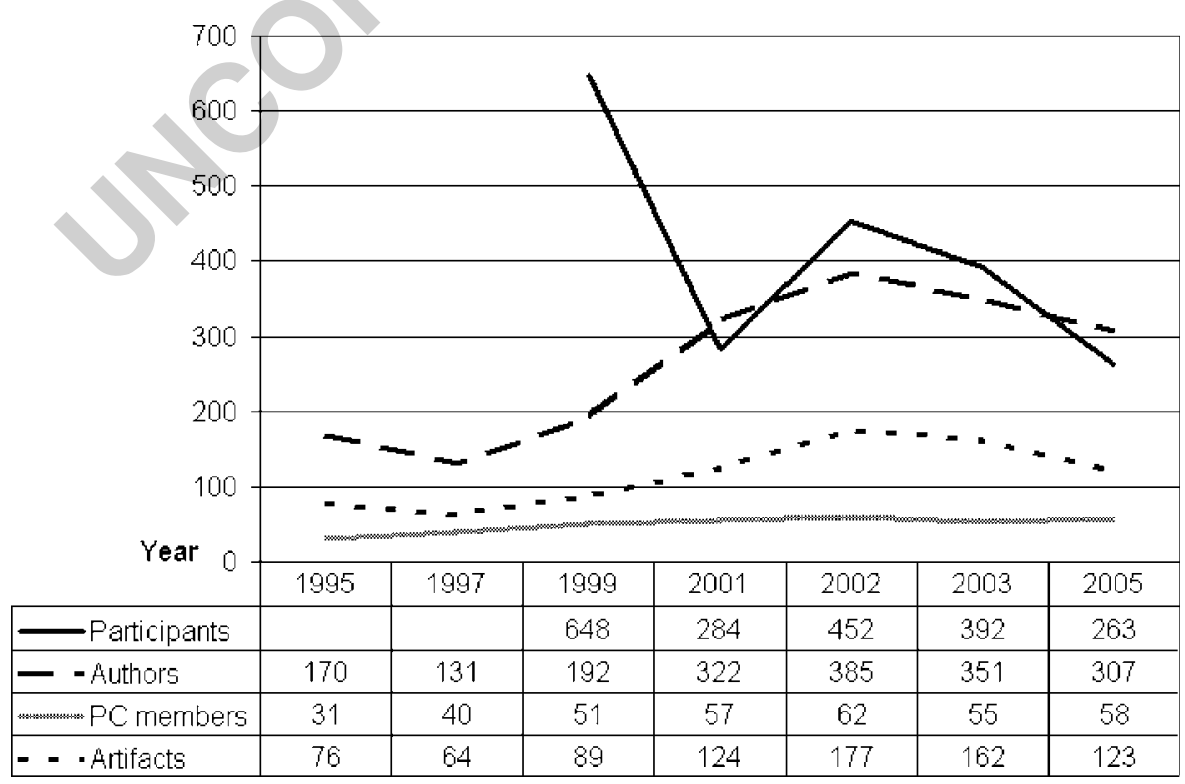

Fig. 1 Number of community members and artifacts 


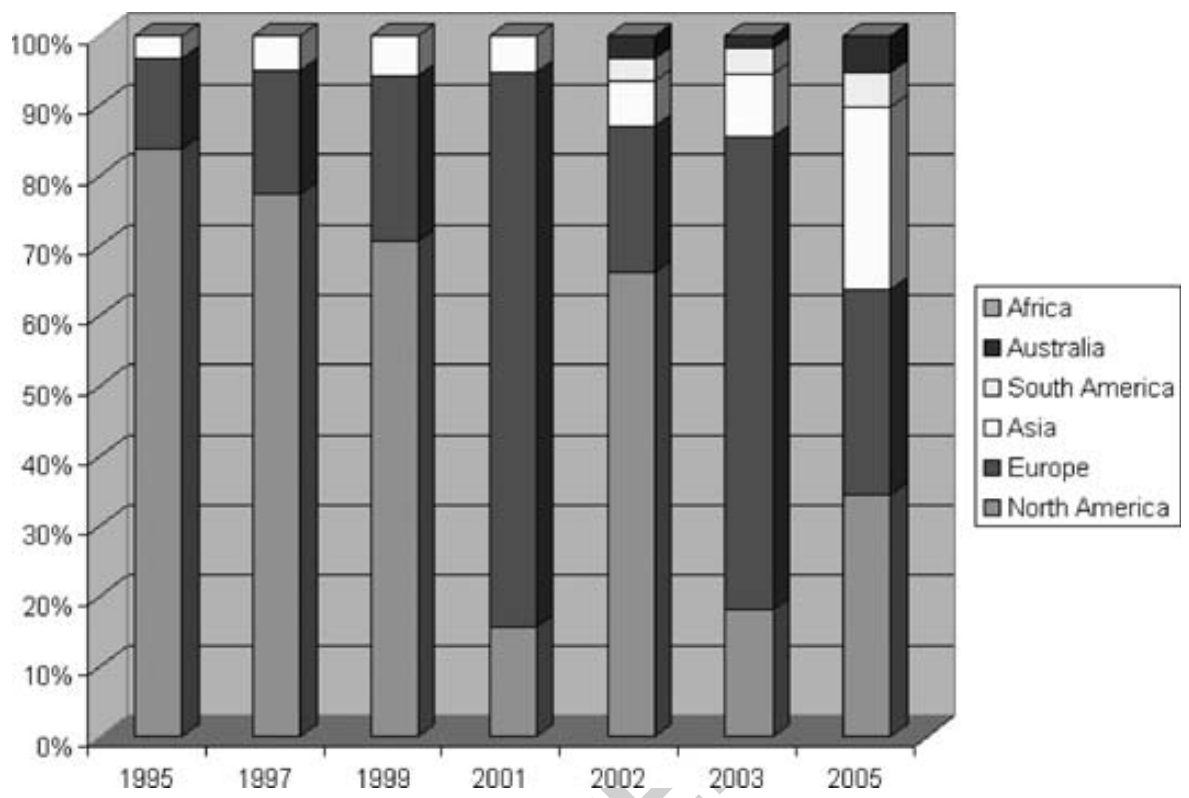

Fig. 2 Regional distribution of PC members by continent

America (all others). Reasons for this relation between location and the regional distribution of PC members will be further explored in the qualitative study below.

In Fig. 3 we see the regional distribution of authors for all past CSCL conferences. Again, we see a relation between conference location and the regional distribution of authors similar to what we saw for the PC members. Participation of European authors was strongest in those years when the conference took place in Europe (2001 and 2003). The highest share of Asian authors can be seen for the conference in Asia (2005). Participation of North American authors was strongest in all other years where the conference took place in North America. Over the years, the regional distributions of PC members and authors seem to lead to a balanced involvement of North American, European and Asian community members with no or very low involvement of PC members and authors from other continents. It is not clear whether the conference location or the involvement of local experts as PC members trigger the regional distribution of authors. One possible explanation is that local PC members motivate submissions for their own and other local research groups.

A study concerning the International Conference of the Learning Sciences (ICLS) shows a similar relation: For this conference, the meeting place is rotated only within North America, where most members of the program committee are from. This corresponds with a low degree of internationality in the group of authors for ICLS conferences (Kirby, Hoadley \& Carr-Chellman, 2005).

In order to assess the continuity we look at all three groups: (conference) participants, authors and PC members, and at the number of conferences in which they 


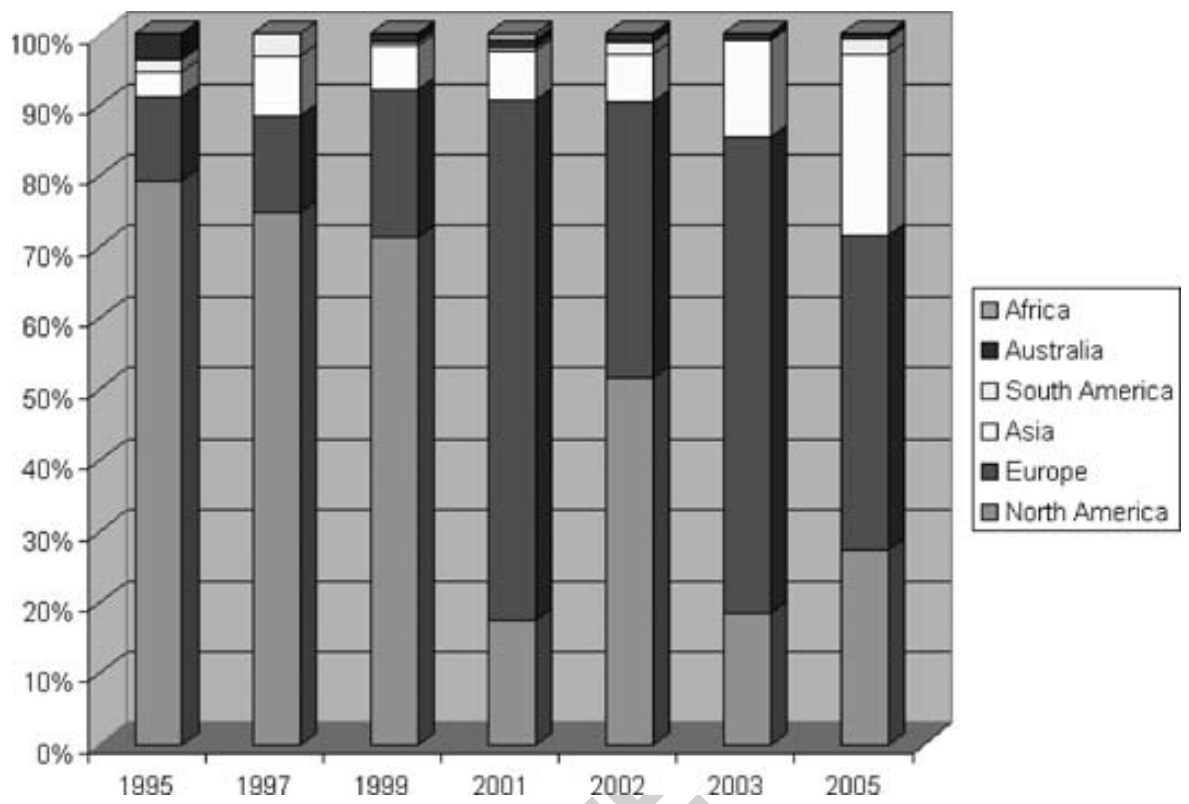

Fig. 3 Regional distribution of authors by continent

were involved (see Fig. 4). In each of these groups we found different degrees of participation, taking the number of conferences in which the community members were involved as a measure.

Surprisingly, about $79 \%$ of all authors contributed only to one conference. About $21 \%$ of all authors contributed to at least two conferences, and only about $8 \%$ of authors (108 out of 1392) contributed to at least three conferences. The numbers for PC members point in the same direction, but show a little bit more continuity:

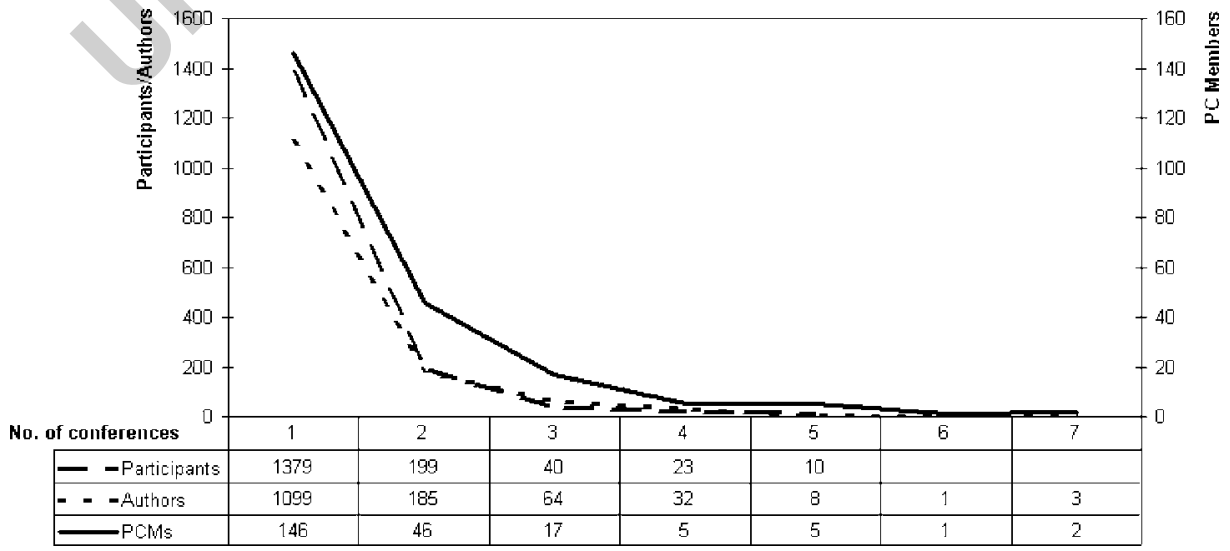

Fig. 4 Continuity of PC members, authors, and participants 
About $66 \%$ of all PC members were involved in only one conference. As we only have participation data for five conferences, the participation figures are not comparable to the figures for the other two groups (authors and PC members). We do, however, see a similar tendency: About $84 \%$ of all participants attended only one conference, and only 10 persons $(0.6 \%$ of all participants $)$ were present at each of the last five conferences.

We (and most other community members to whom we presented these numbers) were surprised by the high percentage of authors who participated in only one CSCL conference $(79 \%)$. One hypothesis was that while the continuity for individuals is quite low (e.g., graduate students don't stay in the field for long), the continuity of research groups should be much higher. In order to evaluate this we recorded the affiliation for the first two conferences. A significant complication for the evaluation was the heterogeneity of affiliations. Without laborious research it is not possible to decide whether "School of W," "Institute of X," "Y Research Group," and "The Z Project," all at the same university, denote the same or different research groups. Therefore, we evaluated continuity simply on a university (or company, etc.) level, which actually should result in a higher continuity as all research groups at one organization are treated as one group. On an individual author basis, $13 \%$ of the authors at the first conference also participated in the second. At the organizational level, $18 \%$ of the organizations represented by authors in the first conference were also represented in the second. Thus, switching from an individual to an organizational level didn't make a large difference with respect to continuity. As this could be an effect of the field's nascence, it would be valuable to extend this analysis to later conferences.

In a further analysis we looked at the quotient of new and recurring authors and PC members for each conference. Somebody is treated as a new author/PC member, if he or she did not participate in that role in any of the previous CSCL conferences; otherwise he or she is treated as a recurring author/PC member. The results are shown in Figs. 5 and 6.

For both groups-authors and PC members-the absolute number and the quotient seem to stabilize for recent conferences. The absolute size of program committees for 2003 and 2005 is 55 and 56 respectively; the number of new PC members for these conferences is 19 and 20 respectively (or about $35 \%$ of all PC members for a given year). For the group of authors, the absolute numbers for 2003 and 2005 are 350 and 284 respectively; the number of new authors is 231 and 193 respectively (or about $67 \%$ of all authors for a given year). This indicates for both groups a relatively stable quotient of "old-timers," who know and represent the existing ideas of the community, and "newcomers," who might bring new ideas to the group. However, the ratio of newcomers in the group of authors (around 67\%) is higher than in the group of PC members (around 35\%).

A second, deeper analysis concerns the "key players" of the community: we take a closer look at those members who participated repeatedly either as authors or as PC members. In order to get comparable group sizes we consider as key PC member those serving on at least three out of all seven program committees (30 out of $222 \mathrm{PC}$ members) and as key authors those who published in at least four out of the seven conference proceedings (44 out of 1392 authors). Table 1 lists these key community members. One interesting point here is that the intersection of those two groups is relatively small (13 persons; see names in bold italics in Table 1). 


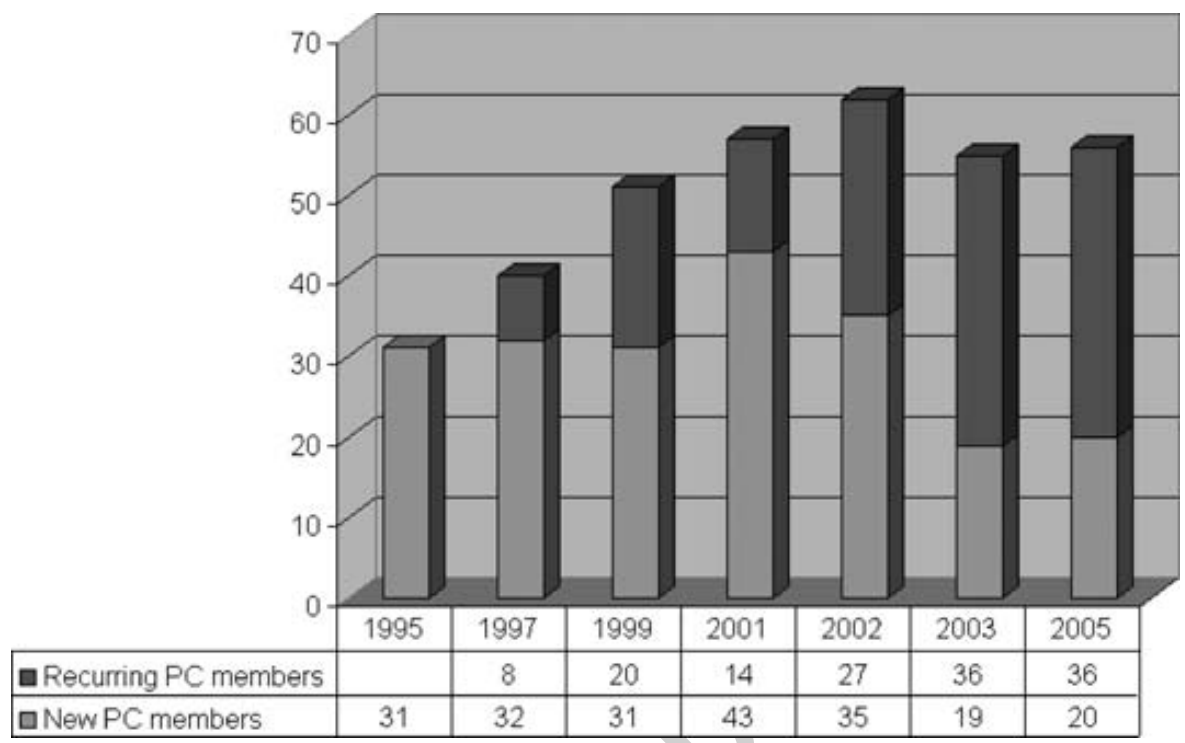

Fig. 5 New and recurring PC members for each conference

Figure 7 shows the regional distribution of the key members (by continent). This reveals a higher continuous engagement of North Americans in the Program Committees on the one hand, and more continuously active authors from Europe on the other hand.

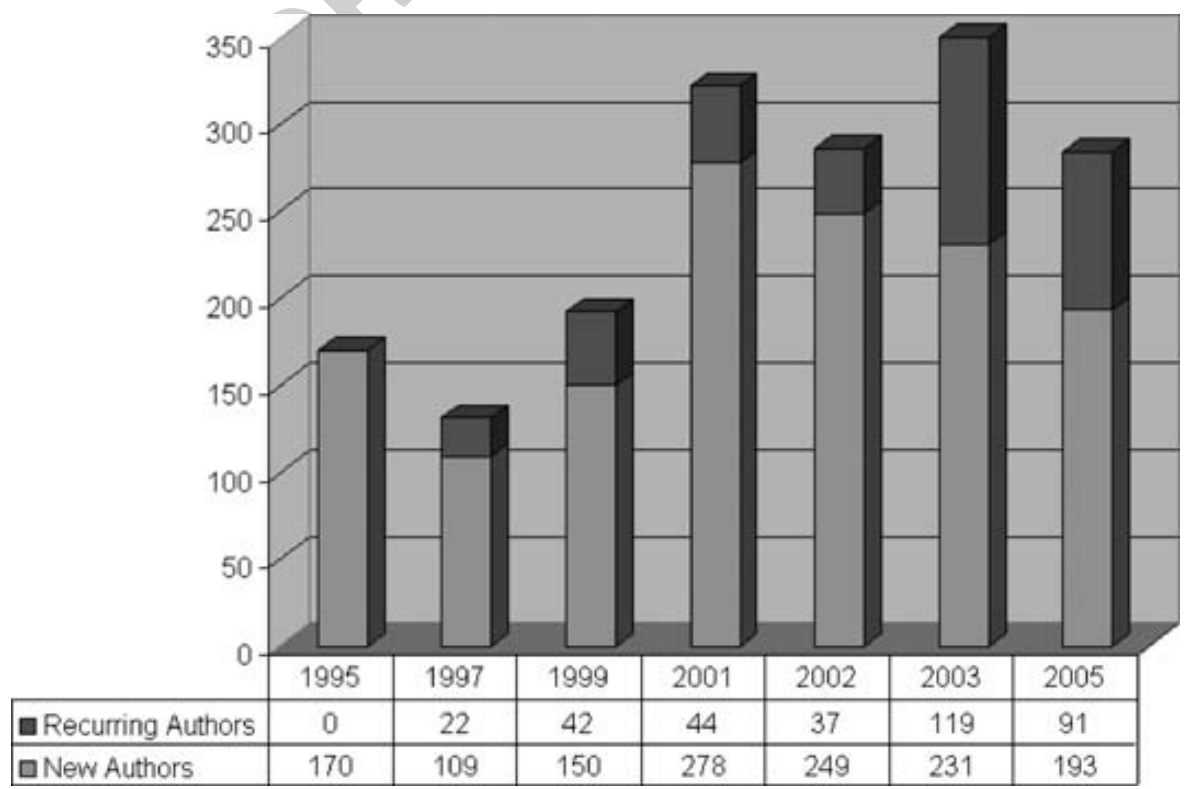

Fig. 6 New and recurring authors for each conference 
Table 1 Authors and PC members who participated in four or more conferences (intersection in bold italics)

\begin{tabular}{|c|c|c|c|c|c|}
\hline $\begin{array}{l}\text { No. of } \\
\text { conf. }\end{array}$ & Authors & & PC members & $\begin{array}{l}\text { No. of } \\
\text { conf. }\end{array}$ & $\mathrm{t} 1.2$ \\
\hline \multirow[t]{17}{*}{4} & de Laat, Maarten & O'Shea, Tim & Bruckmann, Amy S. & \multirow[t]{17}{*}{3} & $\mathrm{t} 1.3$ \\
\hline & Dillenbourg, Pierre & Puntambekar, Sadhana & Collins, Allan & & $\mathrm{t} 1.4$ \\
\hline & Dirckinck-Holmfeld, Lone & Reimann, Peter & Fischer, Gerhard & & $\mathrm{t} 1.5$ \\
\hline & Edelson, Daniel C. & Rummel, Nikol & Fishman, Barry J. & & $\mathrm{t} 1.6$ \\
\hline & Fischer, Frank & Scanlon, Eileen & Gomez, Louis M. & & $\mathrm{t} 1.7$ \\
\hline & Fischer, Gerhard & Schwarz, Baruch B. & Guzdial, Mark & & $\mathrm{t} 1.8$ \\
\hline & Guzdial, Mark & Shirouzu, Hajime & Hall, Rogers & & $\mathrm{t} 1.9$ \\
\hline & Häkkinen, Päivi & Smith, Randall B. & Hoadley, Christopher & & $\mathrm{t} 1.10$ \\
\hline & Hoadley, Christopher M. & Sorensen, Elsebeth K. & Kolodner, Janet L. & & $\mathrm{t} 1.11$ \\
\hline & Järvelä, Sanna & Spada, Hans & Mørch, Anders & & $\mathrm{t} 1.12$ \\
\hline & Kanselaar, Gellof & Stanton, Danaë & Olson, Gary & & $\mathrm{t} 1.13$ \\
\hline & Kaptelinin, Victor & Sugimoto, Masanori & Reimann, Peter & & $\mathrm{t} 1.14$ \\
\hline & Kato, Hiroshi & Suzuki, Hideyuki & Resnick, Mitchel & & $\mathrm{t} 1.15$ \\
\hline & Kolodner, Janet L. & Tholander, Jakob & Stahl, Gerry & & $\mathrm{t} 1.16$ \\
\hline & Kusunoki, Fusako & van Aalst, Jan & Sugimoto, Masanori & & $\mathrm{t} 1.17$ \\
\hline & Lakkala, Minna & Wessner, Martin & Verdejo, M.Felisa & & $\mathrm{t} 1.18$ \\
\hline & Mandl, Heinz L. & & Woodruff, Earl & & $\mathrm{t} 1.19$ \\
\hline \multirow[t]{5}{*}{5} & Erkens, Gijsbert & Gomez, Louis M. & Baker, Michael & \multirow[t]{5}{*}{4} & $\mathrm{t} 1.20$ \\
\hline & Fjuk, Annita & Hakkarainen, Kai & Engeström, Yrjö & & $\mathrm{t} 1.21$ \\
\hline & Lipponen, Lasse & Hoppe, Ulrich & Hakkarainen, Kai & & $\mathrm{t} 1.22$ \\
\hline & Wasson, Barbara & & Lehtinen, Erno & & $\mathrm{t} 1.23$ \\
\hline & & & Ogata, Hiroaki & & $\mathrm{t} 1.24$ \\
\hline \multirow[t]{5}{*}{6} & \multirow{9}{*}{$\begin{array}{l}\text { Hmelo, Cindy E. } \\
\text { Stahl, Gerry } \\
\text { Suthers, Daniel D. }\end{array}$} & \multirow{9}{*}{ Koschmann, Timothy } & Dillenbourg, Pierre & 5 & $\mathrm{t} 1.25$ \\
\hline & & & Hoppe, Ulrich & & $\mathrm{t} 1.26$ \\
\hline & & & O'Malley, Claire & & $\mathrm{t} 1.27$ \\
\hline & & & Pea, Roy & & $\mathrm{t} 1.28$ \\
\hline & & & Suthers, Daniel D. & & $\mathrm{t} 1.29$ \\
\hline \multirow[t]{4}{*}{7} & & & Roschelle, Jeremy & 6 & $\mathrm{t} 1.30$ \\
\hline & & & & & $\mathrm{t} 1.31$ \\
\hline & & & Koschmann, Timothy & 7 & $\mathrm{t} 1.32$ \\
\hline & & & Miyake, Naomi & & $\mathrm{t} 1.33$ \\
\hline
\end{tabular}

We describe the connectivity of the community by analyzing references and coauthorships. First, we look at the references that we rate as weak connections between members of the community. For space reasons we limit the analysis to two snapshots of the community, one from the beginning of the CSCL conference series (1995) and one from a recent conference (2003). Figure 8 shows the reference network for the 1995 conference, Fig. 9 for the one in 2003. The figures include the references to all authors in the community that exist in artifacts from the top 88 authors (i.e., all authors who contributed to at least three conferences from 19952003). At a first glance it can be seen that the number of nodes (representing authors and referenced authors) increases from 1995 to 2003. This is not surprising 


\section{Key PC Members $\quad$\begin{tabular}{l}
\hline North America \\
$\square$ Europe \\
$\square$ Asia
\end{tabular}}

Key Authors
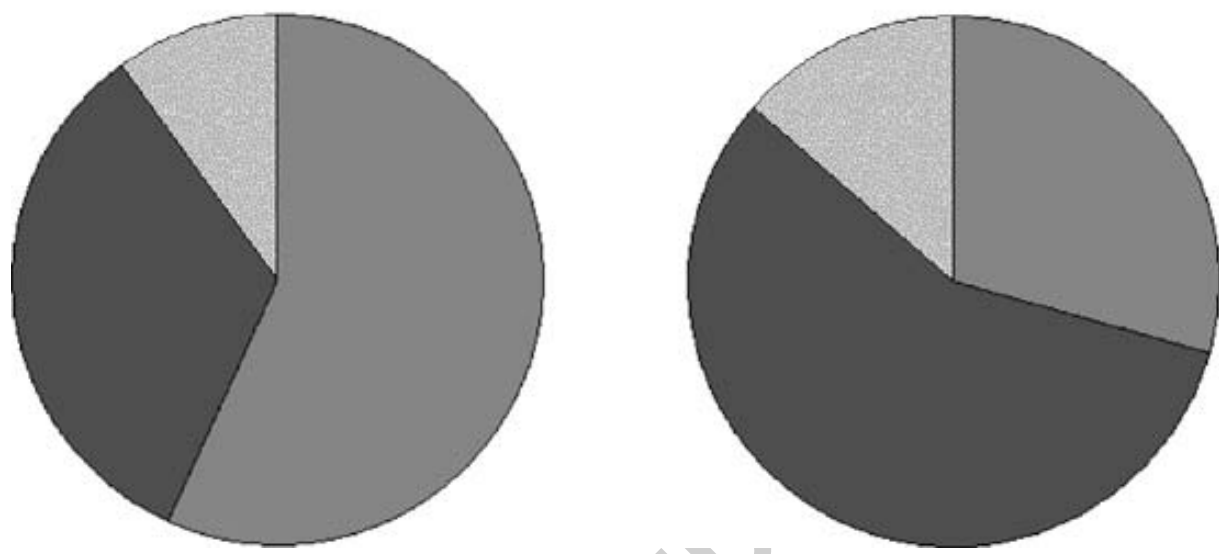

Fig. 7 Authors and PC members at three or more conferences, by continent

because over the years the number of authors increases and more CSCL-related papers exist, e.g., in proceedings of previous conferences. But the interesting point in these figures is the growing number of international references. While in 1995 most references are to authors in the same country, in 2003 we see more international connections. Concerning the large network in the middle of Fig. 9, it

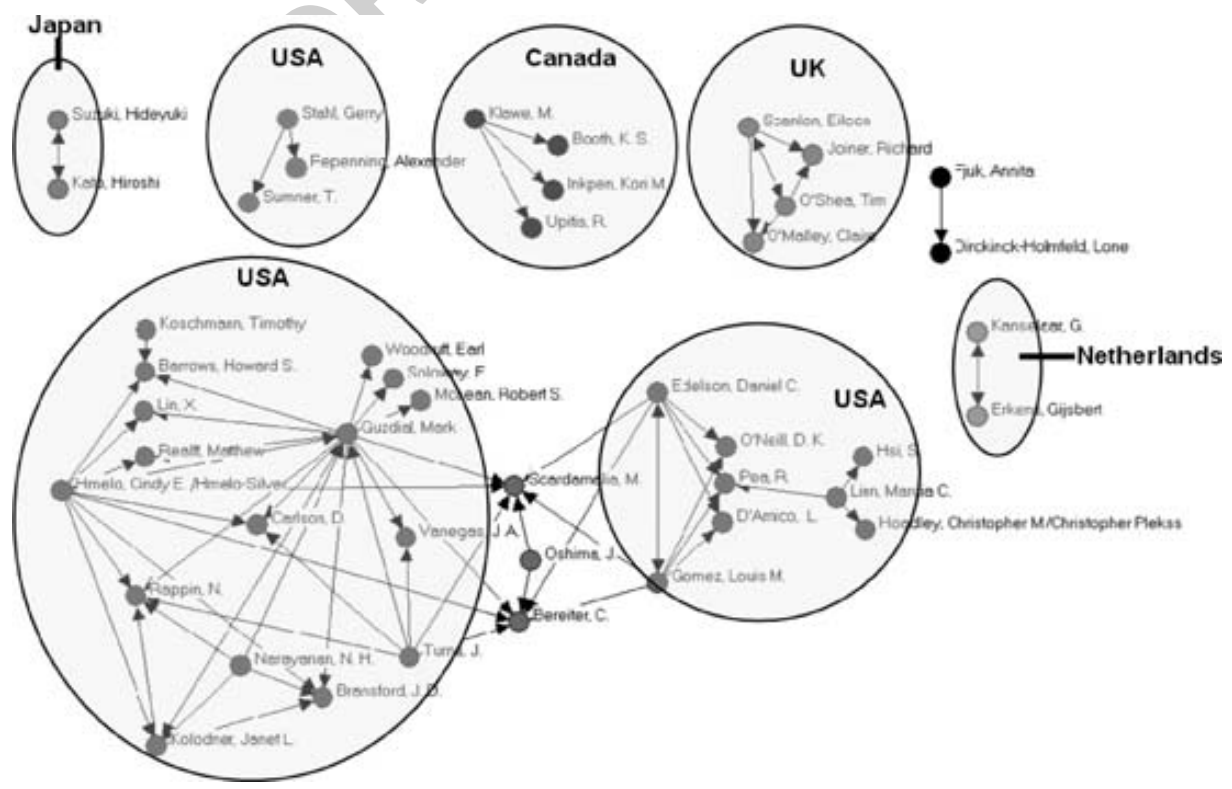

Fig. 8 Reference network in 1995 


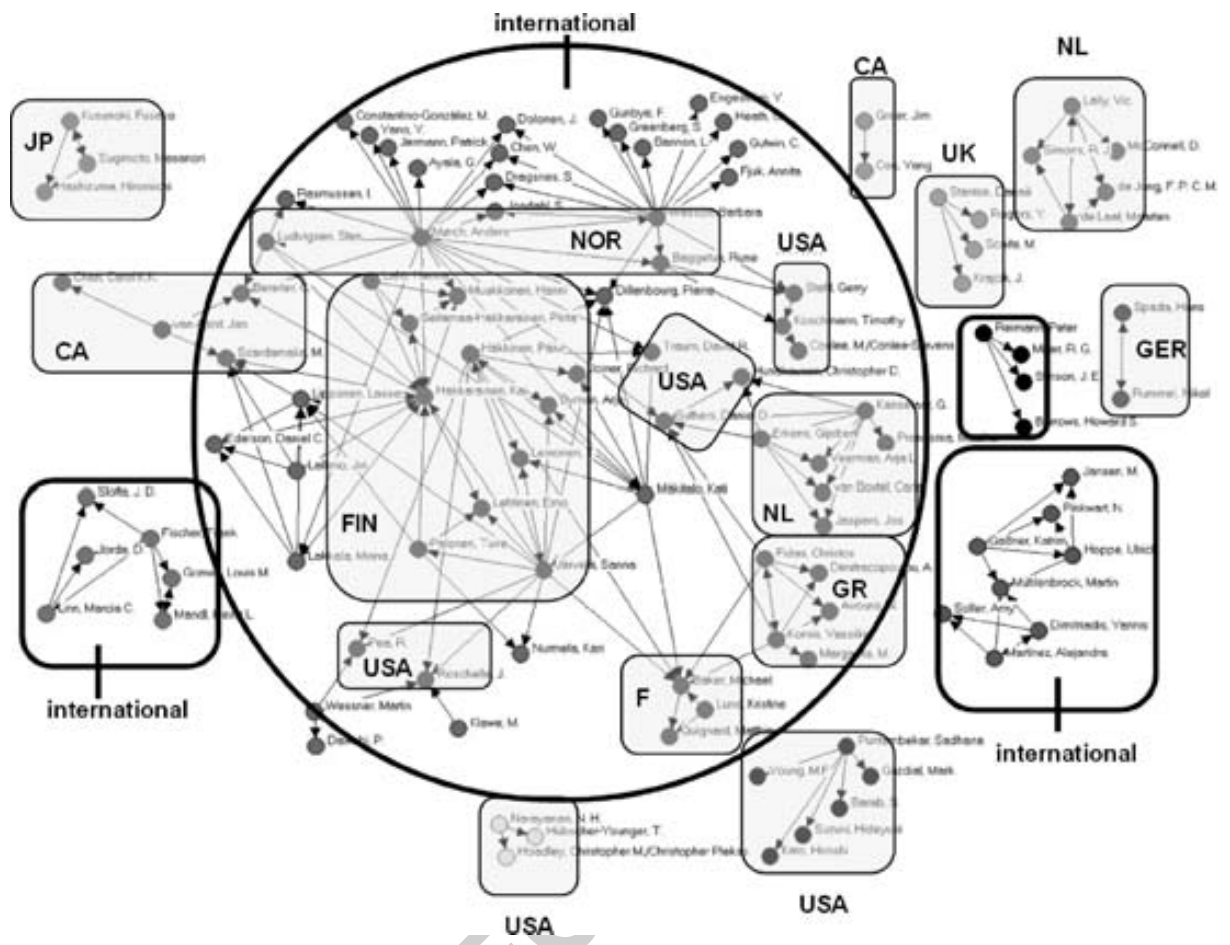

Fig. 9 Reference network in 2003

should be pointed out that national sub-groups (e.g., from France, Greece, Finland, 340 Sweden, Canada, USA) are connected by their reference to the same authors. 341

In a second step, we try to verify this observation of growing international 342 connectivity by analyzing the co-authorships, which we rate as strong connections, 343 between the members of the community. Figures 10 and 11 show the co-authorship networks of 1995 and 2003 respectively, abstracted to reveal the countries of the top 88 co-authors contributing to the data. This data confirms the observation of a growing international connectivity. Here-as well as in the case of references-not only does the number of nodes increase, but the international connectivity grows as well.
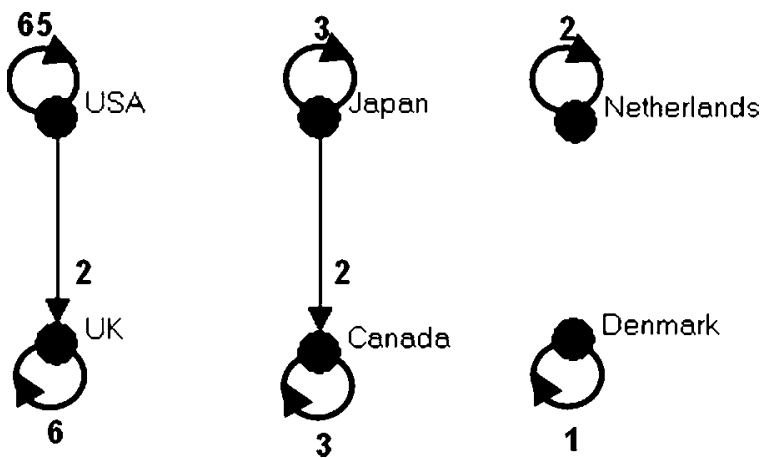

Fig. 10 Co-authorship network in 1995 

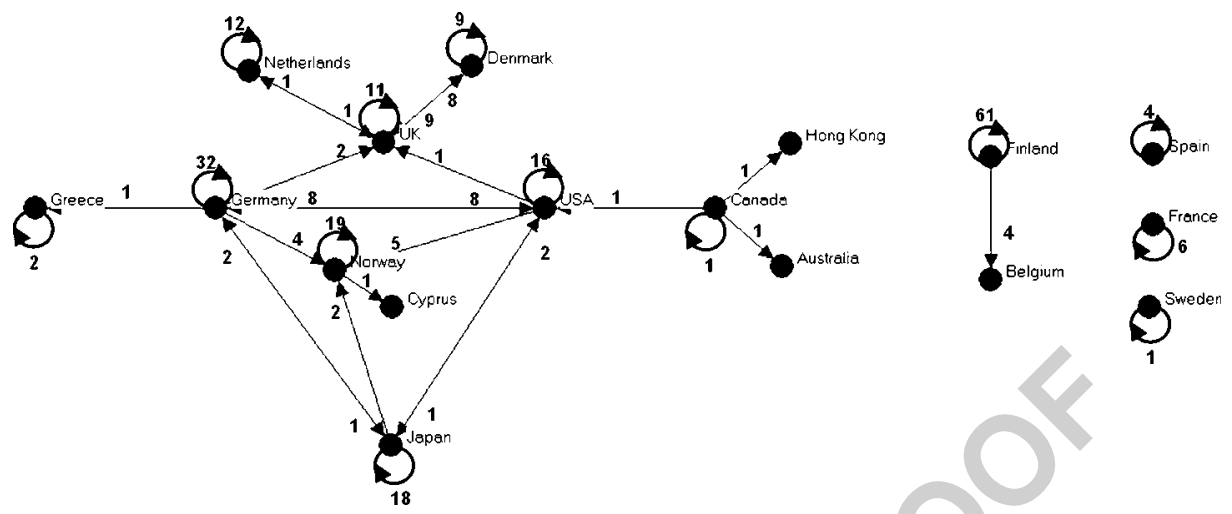

Fig. 11 Co-authorship network in 2003

For 2003, we emphasize the close connection between authors from UK and Denmark ( 9 and 8 co-authorships, respectively) as well as from USA and Germany (each having 8 co-authorships). A further interesting point is the large number of Finnish-only co-authorships (61). This indicates a close-meshed network with less connection to other countries. On the other hand, the view from the references (Fig. 9) suggests that Finnish authors are well positioned in the international (weaker) network of references.

To sum up, these findings support the assumption that the connectivity over regional boundaries grew over the last 10 years. While the quantitative analysis of the CSCL community provided some answers to our research questions, many observations are difficult to interpret. In order to learn more about the policies and motives involved, we conducted a qualitative study that is reported in the following section.

\section{Results from the Qualitative Study}

Here, we present the main results of the qualitative study, which was conducted by e-mail. As already described above, this study addressed PC/conference chairs, international co-authors, and conference participants. The overall response rate was relatively high: more than half of the "officials" (12 of 22; at least one from each conference), 11 of 34 co-authors (approximately one third, concerning all 9 intercontinental co-authorships in 2005), and more than half of the randomly selected conference participants (15 of 28$)$ responded. We rate this as an indicator that the community is of high relevance for its members. In the following, results are presented concerning conference organization, international co-authorship, and participation in conferences.

Table 2 shows the policy for selecting the conference locations as reported by conference or program chairs. For the first conference, we see that Tim Koschmann, the initiator of the CSCL conference series, also influenced the selection of the 
Table 2 Policy for the selection of conference location, (no. = number of respondents for the dimension/category)

\begin{tabular}{|c|c|c|c|c|c|c|c|c|}
\hline Selection of conference location & No. & 1995 & 1997 & 1999 & 2001 & 2002 & 2003 & 2005 \\
\hline Tim Koschmann & 1 & $X$ & & & & & & \\
\hline $\begin{array}{l}\text { Decision at the previous conference } \\
\text { Decision by... }\end{array}$ & 5 & & $\mathrm{X}$ & $\mathrm{X}$ & $\mathrm{X}$ & $\mathrm{X}$ & & $\mathrm{X}$ \\
\hline $\begin{array}{l}\text {...the CSCL-community (Voting at } \\
\text { business meeting) }\end{array}$ & 5 & & & & $\mathrm{X}$ & $\mathrm{X}$ & $\mathrm{X}$ & \\
\hline ...formal process of ISLS & 1 & & & & & & & $\mathrm{X}$ \\
\hline $\begin{array}{l}\text { Organizational reasons (traffic, easy } \\
\text { to reach, all at the same place) for } \\
\text { the location }\end{array}$ & 2 & & & & & & $\mathrm{X}$ & $\mathrm{X}$ \\
\hline
\end{tabular}

conference location. For nearly all other conferences the decision about the upcoming location was made at the previous conferences (for 5 conferences, confirmed by 5 respondents). For the later conferences, we can state that the community itself had an influence on the selection of the conference location by voting at the business meetings. For the last conference, in 2005, a formal ISLS process was initiated.

The conference chairs have great influence on the membership in the Program Committee, as they select the members based on their own knowledge about either the work of the potential members ( 6 of 12) or about the person her/himself ( 4 of 12) (see Table 3). Another factor for selecting a PC member is whether or not he or she was a PC member of the previous conference ( 5 of 12 ), with preference being granted to those who were. Table 3 also reveals that conference chairs are increasingly aiming to establish an international balance on the Program Committee.

376 377 378 379 380 381 382 383 384 385 386 387 388

Table 3 Policy for the selection members of program committees (no. = number of respondents for the dimension/category)

\begin{tabular}{|c|c|c|c|c|c|c|c|c|}
\hline Selection of PC members & No. & 1995 & 1997 & 1999 & 2001 & 2002 & 2003 & 2005 \\
\hline Known people -people... & 8 & & & & & & & \\
\hline $\begin{array}{l}\text { whose work was known } \\
\text { as CSCL-related }\end{array}$ & 6 & $\mathrm{X}$ & $\mathrm{X}$ & & $\mathrm{X}$ & $\mathrm{X}$ & $\mathrm{X}$ & \\
\hline $\begin{array}{l}\text { who were personally known } \\
\text { by PC/conference chairs } \\
\text { (and fit the job) }\end{array}$ & 4 & & & $\mathrm{X}$ & $\mathrm{X}$ & $\mathrm{X}$ & & $\mathrm{X}$ \\
\hline $\begin{array}{l}\text { From PC member lists of } \\
\text { previous conferences }\end{array}$ & 5 & & & $\mathrm{X}$ & & $\mathrm{X}$ & $\mathrm{X}$ & $\mathrm{X}$ \\
\hline Geographical reasons & 5 & & & & & & & \\
\hline More Europeans & 2 & & & $\mathrm{X}$ & $\mathrm{X}$ & & & \\
\hline $\begin{array}{l}\text { First EU, than extension } \\
\text { towards others }\end{array}$ & 1 & & & & & & $\mathrm{X}$ & \\
\hline Geographical balance & 1 & & & & & & & $\mathrm{X}$ \\
\hline Proposal for four locals & 1 & & & & & & & $\mathrm{X}$ \\
\hline Random & 1 & & & & $\mathrm{X}$ & & & \\
\hline Only one person per institution & 1 & & & & & & & $\mathrm{X}$ \\
\hline
\end{tabular}


Table 4 shows details about the policy for selecting papers and posters. Here we have to state that the first four factors (size of proceedings, number of paper tracks, number of meeting rooms, duration of conference) were given as examples in the questions sent to the organizers. This is reasoned from the ideas of reviewers discussed in an earlier version of this paper. The organizers mostly confirm the reviewers' assumptions (see Table 4 for details).

Another important topic is that chairs have to balance their selection between a smaller number of high quality full papers and a higher number of short papers or posters:

We tried to call posters "short papers" so that they might count for getting travel support for authors, and stressed that they had full peer review. We were successful in making the poster sessions an important part of the program by locating them strategically within the daily receptions. So we accepted a limited number of long papers and lots of posters. (Participant (P) 5.1).

The concept of accepting a few long papers and more short/interactive papers was used for all conferences since 2002. This helps to explain the relatively high number of authors since 2002, as shown in Fig. 1.

The evaluation of the answers concerning the acceptance rate was quite difficult. Half of the respondents did not remember it. Where an acceptance rate was stated it was often labelled as "approximately." For the first conference, a high acceptance rate was mentioned and reasoned as follows:

It was a new conference and we wanted to encourage participation. (P1.1).

Table 4 Influencing factors for submission acceptance and acceptance rate (no. = number of respondents for the dimension/category)

\begin{tabular}{|c|c|c|c|c|c|c|c|c|}
\hline $\begin{array}{l}\text { Influencing factors for } \\
\text { selecting papers/posters }\end{array}$ & No. & 1995 & 1997 & 1999 & 2001 & 2002 & 2003 & 2005 \\
\hline Size of proceedings & 5 & $\mathrm{X}$ & $\mathrm{X}$ & & & $\mathrm{X}$ & $\mathrm{X}$ & $\mathrm{X}$ \\
\hline No. of paper tracks & 6 & $\mathrm{X}$ & $\mathrm{X}$ & $\mathrm{X}$ & & $\mathrm{X}$ & $\mathrm{X}$ & $\mathrm{X}$ \\
\hline No. of meetings rooms & 6 & $\mathrm{X}$ & $\mathrm{X}$ & $\mathrm{X}$ & & $\mathrm{X}$ & $\mathrm{X}$ & $\mathrm{X}$ \\
\hline Duration of conference & 6 & $\mathrm{X}$ & $\mathrm{X}$ & $\mathrm{X}$ & & $\mathrm{X}$ & $\mathrm{X}$ & $\mathrm{X}$ \\
\hline $\begin{array}{l}\text { Mix of scholars and } \\
\text { graduate students }\end{array}$ & 1 & $\mathrm{X}$ & & & & & & \\
\hline No. of slots & 2 & $\mathrm{X}$ & & & $\mathrm{X}$ & & & \\
\hline $\begin{array}{l}\text { Short papers instead of } \\
\text { posters, more short } \\
\text { papers to foster more } \\
\text { regional guys presenting } \\
\text { their work }\end{array}$ & 2 & & & & & $\mathrm{X}$ & & $\mathrm{X}$ \\
\hline $\begin{array}{l}\text { Maximum of relation } \\
\text { between full papers, work } \\
\text { in progress and posters }\end{array}$ & 2 & & & & & & $\mathrm{X}$ & \\
\hline Quality of reviews & 1 & & & & & & & $\mathrm{X}$ \\
\hline Acceptance rate & & & & & & & & \\
\hline Don't remember & 6 & & & & & & & \\
\hline Acceptance rate & 6 & $70 \%$ & $?$ & $30 \%$ & $30 \%$ & $17 \%, 45 \%$ & $27 \%$ & $31 \%$ \\
\hline
\end{tabular}


Table 5 Reasons for participation in international groups of co-authors

\begin{tabular}{lll}
\hline $\begin{array}{l}\text { Reasons for international } \\
\text { co-authoring }\end{array}$ & $\begin{array}{l}\text { No. } \\
\text { (persons) }\end{array}$ & $\begin{array}{l}\text { No. (author groups }= \\
\text { papers) }\end{array}$ \\
\hline Personal connections & 5 & 4 \\
$\begin{array}{l}\text { Stimulated by NSF/DFG } \\
\quad \text { orkshop series }\end{array}$ & 5 & 4 \\
$\begin{array}{l}\text { International project } \\
\text { Different, interdependent }\end{array}$ & 2 & 2 \\
$\quad$ disciplines & 1 & 1 \\
$\quad \begin{array}{l}\text { Continuing cooperation } \\
\text { after position change }\end{array}$ & 1 & 1 \\
\hline
\end{tabular}

Most of the other conferences have an acceptance rate of approximately $30 \%$ for long papers. One exception was the first year with the new concept of including a larger number of short papers (2002). In this instance, the acceptance rate for long paper was extremely low, at $17 \%$ (with an overall acceptance rate of $45 \%$ ).

In the quantitative analysis we saw an increasing number of international coauthorships in the community. The qualitative study aimed at further exploring this development. In more detail, we asked authors about their reasons to co-author a paper with international colleagues, the factors that support and constrict international co-authoring, and the development of their involvement in international co-authoring.

Table 6 Factors that support international co-authoring

\begin{tabular}{|c|c|c|}
\hline Supporting factors & $\begin{array}{l}\text { No. } \\
\text { (persons) }\end{array}$ & $\begin{array}{l}\text { No (author groups = } \\
\text { papers) }\end{array}$ \\
\hline Sharing... & 6 & 5 \\
\hline ...common interests & 2 & 2 \\
\hline $\begin{array}{l}\text {...prior experiences in int. } \\
\text { research }\end{array}$ & 1 & 1 \\
\hline $\begin{array}{l}\text {...established research } \\
\text { partnerships }\end{array}$ & 1 & 1 \\
\hline ...same data, data analysis & 1 & 1 \\
\hline ...resources & 1 & 1 \\
\hline Technical support & 5 & 5 \\
\hline E-mail & 3 & 3 \\
\hline Phone & 1 & 1 \\
\hline Chat tools & 1 & 1 \\
\hline WISE environment & 1 & 1 \\
\hline $\begin{array}{l}\text { Complementary interests, } \\
\text { skills, } \\
\text { interdependent } \\
\text { knowledge }\end{array}$ & 4 & 3 \\
\hline $\begin{array}{l}\text { Opportunity to visit } \\
\text { research partners }\end{array}$ & 3 & 3 \\
\hline Funding by DFG & 1 & 1 \\
\hline Time shift & 1 & 1 \\
\hline
\end{tabular}

t6.1

t6.2

t6.3

t6.4

t6.6

t6.7

t6.8

t6.9

t6.10

t6.11

t6.12

$\mathrm{t} 6.13$

t6.14

t6.15

t6.16 
Table 7 Factors that constrict international co-authorships

\begin{tabular}{lll}
\hline Constricting factors & $\begin{array}{l}\text { No. } \\
\text { (persons) }\end{array}$ & $\begin{array}{l}\text { No (author groups }= \\
\text { papers) }\end{array}$ \\
\hline Different... & $\mathbf{4}$ & $\mathbf{3}$ \\
...disciplines & 2 & 1 \\
...locations/distance & 2 & 2 \\
Time constraints & 2 & 2 \\
Missing joint project & 1 & 1 \\
$\begin{array}{l}\text { Main authors never met } \\
\text { before }\end{array}$ & 1 & 1 \\
$\begin{array}{l}\text { Chat = complicated } \\
\text { communication }\end{array}$ & 1 & 1 \\
$\quad$
\end{tabular}

Our collaboration started as part of the NSF-DFG workshop series... (Respondent (R) 1.5).

Some other reasons were given by one or two person(s) (see Table 5). Some of the personal connections were developed during these workshops:

The international co-authorship emerged from personal connections that developed during discussions within a NSF-DFG sponsored workshop series. (R 8.1).

Table 6 shows the answers concerning supporting factors for the international groups of authors. Here we build categories "Sharing" and "Technical support" to integrate the different dimensions of the same answer. These different dimensions are indented in the following rows. The numbers behind the categories are the sum of people and author groups, respectively, whose answer included one of the corresponding dimensions.

Table 8 Development of international co-authorships

\begin{tabular}{lll}
\hline $\begin{array}{l}\text { Development of } \\
\text { international co-authorships }\end{array}$ & $\begin{array}{l}\text { No. } \\
\text { (persons) }\end{array}$ & $\begin{array}{l}\text { No (author groups }= \\
\text { papers) }\end{array}$ \\
\hline More & 5 & 3 \\
Continuing & 2 & 2 \\
$\begin{array}{l}\text { No/Yes (unintended } \\
\text { interpretation) }\end{array}$ & 3 & 3 \\
No answer & 1 & 1 \\
\hline
\end{tabular}


Table 9 Reasons for participation in a CSCL-conferences

\begin{tabular}{lc}
\hline Reason for participation & No. \\
\hline Paper/Presentation & $\mathbf{9}$ \\
Interest in topic & $\mathbf{9}$ \\
Close to research interest & 2 \\
Be part of the community & 2 \\
Favorite conference & 1 \\
Outlet of my work & 1 \\
Introduced by a colleague & 1 \\
Meet with collegues from ISLS & 1 \\
Nurture the international nature of ISLS & 1 \\
No answer & $\mathbf{1}$ \\
\hline
\end{tabular}

t9.1

t9.2

t9.3

t9.4

t9.5

t9.6

t9.7

t9.8

t9.9

$\mathrm{t} 9.10$

t9.11

450

451

Supporting factors: similar ideas and interests from the outset (R 8.1).

On the other hand, one third of the respondents emphasize that they have complementary interests, e.g., skills, interdependent knowledge:

Complementary expertise supported our work (R 4.4).

One interesting point is the high number of answers (5) concerning the availability of technical communication and cooperation tools like e-mail (3):

There is no obstacle, with email and cheap telephone. (R 7.1).

Table 6 shows all supporting factors mentioned by the respondents.

In general, the respondents mentioned fewer constricting factors in comparison to supporting factors (see Table 7). More than one third of the respondents mentioned different disciplines (2) or locations (2) as constricting factors; other factors are stated only by a minority of the respondents (see Table 7).

Table 8 shows answers concerning the development of international co-authorships. Five (of 12) respondents stated that there was an increasing amount of international co-authoring, while 2 stated that there was a continuing amount. Three people answered "yes" or "no," which we rate as an unintended interpretation ("other" instead of "more") of the question regarding the development of international co-authorships.

Table 10 Participation of co-authors 
Table 11 Research fields of respondents

\begin{tabular}{lc} 
Research field & No. \\
\hline CSCL & 5 \\
Broader/parallel field & 5 \\
CSCW & 1 \\
Software architecture & 1 \\
Ethnographic research in education & 1 \\
Developmental psychology & 1 \\
No answer & 1 \\
\hline
\end{tabular}

$\mathrm{t} 11.1$

$\mathrm{t} 11.2$

$\mathrm{t} 11.3$

$\mathrm{t} 11.4$

$\mathrm{t} 11.5$

$\mathrm{t} 11.6$

$\mathrm{t} 11.7$

$\mathrm{t} 11.8$

\section{Participation in Conferences}

In order to explore reasons for participating in a conference, we contacted 28 participants and 15 of them responded. They were equally distributed with regard to the different levels of participation and their location (North America and Europe only). In general, we found no differences in reasons for participation between the different levels of participation or between participants from Europe and North America.

As reasons for the participation in a CSCL conference, more than half of the respondents ( 9 of 15) mentioned the presentation of a paper, poster, etc. (see Table 9). The same number of respondents emphasized their interest in the topic of CSCL; here we again built a category to integrate the different dimensions, such as: "close to research interest" or "be part of a community."

For jointly authored papers we also wanted to know to what extent co-authors attended the conference as well. This question was answered inconclusively: While 8 (of 15) respondents answered with "no" or "only one," 6 respondents answered with "yes" (see Table 10). Please note that people who participated in more than one conference can answer "both."

Nearly all of the respondents (14 of 15; one person did not answer this question) confirmed that the 9/11 terror attack in New York did not effect their travel policy. Unfortunately, we only reached those people who participated, and not those who did not participate (e.g., due to the 9/11 event).

The question about the research field reveals another interesting point. Only one third of the respondents regard CSCL as their main research field. Another third

Table 12 Discipline of respondents

\begin{tabular}{ll} 
Discipline & \\
\hline Computer science/Information science & 5 \\
Education & 4 \\
Psychology & 4 \\
"Psychology" & 2 \\
"Educational psychology" & 2 \\
Anthropology & 1 \\
Conversation analysis & 1 \\
Knowledge building & 1 \\
No answer & 1
\end{tabular}


stated that their research field is a broader or parallel field. See, for example, the following statements:

"I am researching learning with new media, which seems to be a little bit broader than original CSCL meaning." or "Since the CSCL conference rarely have anything about learning at work etc. it does not really capture my interest."

Other research fields were mentioned by one person for each case (see Table 11 for detail).

Furthermore, we can state that the group of respondents, at least, tackle these research fields from within different disciplines: Computer Science (5 of 15), Education (4) or Psychology (4). For other disciplines that are mentioned by only one respondent see Table 12.

\section{Discussion}

The descriptive statistics of the CSCL community provide new insights about the development, continuity, and connectivity in the community. However, there are a number of weaknesses and limitations of this quantitative approach. One weakness is given by the quality of the data. Some data is not available in electronic form, which required fault-prone manual data recording. Other data (e.g., the lists of participants for the 1995 and 1997 conferences) is no longer available at all. Also, existing data is incomplete (e.g., onsite registrations for some conferences) or inconsistent (e.g., different authors are stated for a paper in different sources). In addition, the names of members (e.g., by marriage) and their institutions change as members move from one institution to another etc.

Furthermore, there is no consensus as to what exactly constitutes the CSCL community or what constitutes membership. For example, the role of the conference 2001 in Maastricht is unclear. It was announced as "Euro-CSCL" and therefore it might have been less interesting for non-Europeans to participate in this conference. On the other hand, around $21 \%$ of the program committee members were nonEuropeans. We included it in our analysis because the figures do not differ a lot from the figures for the 2003 conference. This conference also took place in Europe but was announced as a "worldwide" CSCL conference. Others (Hoadley, 2005) did exclude this conference from some parts of their analysis because of its regional focus.

A third issue is the interpretation of the data. For many figures presented in this analysis it is not clear what would be a better or even ideal number for a scientific community as there is still little research on scientific communities.

This led us to combine the quantitative analysis with a qualitative study for selected issues. As we have seen in the qualitative study, quite a number of reasons influence decisions on the community level (e.g., conference location and acceptance rate) as well as on an individual level (e.g., international co-authoring and conference attendance). In the following, the results are discussed in more detail.

The answers concerning the organization of the CSCL conferences show a development towards a more formal process for selecting conference places (by the CSCL community or the ISLS) and a reflection on an international composition of program committees. The selection of PC members seems to draw on a combination of already (personally) known members of the community (who in 
many cases are also part of the program committee of a previous conference) and relatively new ones (whose work is regarded as CSCL related). This selection strategy seems to provide a good balance between continuity ("old-timers") and development ("newcomers").

One interesting point we found in the quantitative data was the rising influence of a Finnish network on the net of references. However, data for the 2005 conference revealed only four Finnish authors (2001: 24, 2002: 19, 2003: 19) and one Finnish conference participant (2001: 23, 2002: 8, 2003: 12). To understand why the involvement of Finnish people dropped in 2005 we asked an expert, a Finnish key player in 2003, for reasons that explain this development. His answer revealed that a lot of reasons influence the submission to and the participation in conferences. One reason is the local policy of whether or not a conference publication is acceptable as part of a doctoral thesis. This seems to change, at least in Finland:

Originally we assumed that articles published in proceedings volumes would be acceptable, but external evaluation revealed that articles published in CSCL conferences were regarded worthless as scientific publications. In order to solve this problem, my research group agreed to pursue only scientific journal articles. [...] I guess that the change in publication strategy did not make participation in CSCL conferences as attractive as before. (Finnish expert).

Another reason is the availability of CSCL related projects. This is at least true for that Finnish research group:

My research network's active participation in Toronto, Stanford, and Maastricht conferences was partially supported by on-going European research projects [...] After finishing these project there was not any more a special need to be so closely involved. (Finnish expert).

Also some answers from people who participated in international co-authorships point to the relevance of existing projects for international cooperation. This is in line with the finding that most of the international co-authorships are stimulated by possibilities to meet, e.g., the NSF/DFG workshop series. In general, funding that fosters meetings between researchers (projects, workshops) seems to be beneficial for the CSCL community. The Finnish expert stated that he will coordinate an upcoming European project that he expects to provide input to the CSCL community:

I expect that this will facilitate both Finnish and European participation again (many candidate EC member countries from Eastern Europe are involved in the project). (Finnish expert).

Besides the support by funded projects or workshops, the relevance of technical infrastructure was mentioned as a supporting factor for international cooperation. We assume that an infrastructure that integrates some of the already available communication and cooperation tools and platforms can foster the cooperation of community members.

One topic the community should be aware of is the heterogeneity of their members. This can be concluded from the research topics and disciplines that we 
recorded from the contacted group of participants. The wide range of research topics implies that the community should work on a profile that clarifies what CSCL is and what it is not. Further research seems to be necessary to get insights from the influential disciplines for the field of CSCL.

\section{Conclusions \& Future Work}

In this paper we presented an analysis of the CSCL community in its first ten years of existence (1995-2005) concerning its development, continuity, and connectivity. This analysis is based on a mix of several approaches: we performed a citation and co-authorship analysis of CSCL conference proceedings and analyzed other sources, including lists of participants and lists of program committee members. These quantitative approaches were supplemented with a qualitative study for selected issues in order to interpret the quantitative results.

Most data confirms that the CSCL community is a lively and mature community with a stable ratio of new and recurring members. Furthermore, the data revealed that the community is increasingly international on all levels of participation. This is related to the rotation of meeting locations and the international composition of the PC members. The CSCL community, especially the members in the core of the community, should be aware of the data presented here as a basis for decisions about meeting locations, composition of program and other committees, etc. In addition, the data could provide help to predict future characteristics of the CSCL community, for example, participation numbers for upcoming conferences. To sum up, for further development of the CSCL community we recommend that the internationality in the program committee as well as the rotation of meeting locations be maintained.

The international connectivity of the community is also increasing, which can be seen in a growing number of citations and co-authorships across different countries. In order to support the international connectivity in the community, authors should take opportunities to work with people from other regions and share the results in (coauthored) papers.

A problem might be seen in the relatively high number of participants, authors, and PC members who participate in or contribute to only one conference. The data showed that the quotient between new and recurring authors and PC members started to stabilize-for PC members, $35 \%$ are newcomers, for authors $67 \%$. The share of recurring authors seems to be quite low. As authors and their products play a very important role in the development of the community; this should be increased. In order to increase the probability that people come back to later conferences, the core group might think about measurements to increase the identification of members with the community. Pragmatically, members could be asked via email or during a CSCL conference to discuss issues related to the continuous participation in the community. This is related to the fact that a significant share of the members does not regard CSCL as their primary scientific community. This could be tackled by working on a clear profile of the CSCL community and its relation to other fields.

The work reported in this paper aims at providing a basis for an ongoing analysis of the CSCL community and for the design of its future. As a basis for further work, 
the data of the quantitative and qualitative studies reported here is available at http://www.cscl-community.org. Possible extensions include:

- Updating the data for each new CSCL conference in order to provide current 641 data on its development to the community.

- Also recording references and co-authorships of authors who contributed only to one or two conferences in order to learn more about the less active authors and how they are distributed and connected in the community.

- Splitting up the artifacts in posters and short and full papers for a more finegrained analysis of development, continuity, and connectivity of the community. (It could make sense to also include submissions that have been rejected, e.g., because of space limitations in the conference program).

- Further specifying citations, e.g., in order to identify the publication types, series, or even individual publications that are most influential to the community.

- Including information about disciplines of participants, authors, and PC members in order to analyze the multi- or inter-disciplinary nature of the community.

- Developing further methods to analyze the development, continuity, and connectivity of the community on a research-group level in addition to the individual and regional levels that are the focus of this paper.

- Performing a social network analysis in order to identify, for example, subgroups and cliques. Using more elaborate analysis methods (e.g., Chen \& Carr, 1999), major research fronts and the evolution of ideas, research topics or methodologies in the community can be identified.

- Providing a technical infrastructure that serves as a repository for the community, supports a continuous community analysis, and fosters communication and cooperation between community members.

The approach taken here-a combination of citation and co-authorship analysis and the analysis of other sources, such as lists of participants, authors, and PC members-should also be applicable to other scientific communities. It would be beneficial to compare figures and their development in different communities. This should provide a better basis to characterize and-based on this-advance the CSCL community.

Acknowledgments The authors thank the reviewers for many helpful comments on an earlier version of this paper. Thanks also to Gerry Stahl and Chris Hoadley who provided many ideas and hints for our community analysis. We are grateful to all participants of our qualitative study and to Marjo Krebbeks, Roy Pea, Jeremy Roschelle, Gerry Stahl, Barbara Wasson and Jie-Chi Yang who provided lists of participants for several CSCL conferences.

\section{References}

Chen C., \& Carr L. (1999). Trailblazing the literature of hypertext: author co-citation analysis (19891998). Proceedings of the tenth ACM Conference on Hypertext and Hypermedia (pp. 51-60), ACM Press.

Cho H., Stefanone Mi., \& Gay G. (2002). Social information sharing in a CSCL community. In G. Stahl (Ed.), Proceedings of the international conference on computer support for collaborative learning 2002 (pp. 43-50). Mahwah, NJ: Lawrence Erlbaum Associates (LEA).

Dillenbourg P., Eurelings A., \& Hakkarainen K. (2001). European perspectives on computer-supported collaborative learning. Proceedings of the First European Conference on Computer 
Support for Collaborative Learning (EuroCSCL 2001). Mc Luhan Institute: Maastricht, The Netherlands.

Fischer F., Bouillon H., Mandl H., \& Gomez L. (2003). Scientific principles in Pasteur's quadrant: Integrating goals of understanding and use in learning environment research. In B. Wasson, S. Ludvigsen \& U. Hoppe (Eds.), Designing for change in networked learning environments: Proceedings of the CSCL 2003 in Bergen, Norway (pp. 493-502). Dordrecht: Kluwer.

Garfield E. (1979). Citation indexing: Its theory and application in science, technology and humanities. New York: John Wiley \& Sons, Inc.

Garfield E., Sher I. H., \& Torpie R. J. (1964). The use of citation data in writing the history of science. Philadelphia: Institute for Scientific Information.

Hall R., Miyake N. \& Enyedy N. (Eds.). (1997). Proceedings of CSCL '97: The Second International Conference on Computer Support For Collaborative Learning. Mahwah, NJ: Lawrence Erlbaum Associates (LEA).

Hoadley C. M. (2005). The shape of the elephant: Scope and membership of the CSCL community. In T. Koschmann, D. D. Suthers \& T.-W. Chan (Eds.), Computer-Supported Collaborative Learning (CSCL) 2005. Taipei, Taiwan: International Society of the Learning Sciences.

Hoadley C. M., \& Roschelle J. (Eds.) (1999). Proceedings of the Computer Support for Collaborative Learning (CSCL) 1999 Conference. Mahwah, NJ: Lawrence Erlbaum Associates (LEA).

Horn D. B., Finholt T. A., Birnholtz J. P., Motwani D., \& Jayaraman S. (2004). Six degrees of Jonathan Grudin: A social network analysis of the evolution and impact of CSCW research. Proceedings of the ACM Conference on Computer Supported Cooperative Work (pp. 582-591), Chicago, IL.

Kessler M. M. (1963). Bibliographic coupling between scientific papers. American documentation, 14(1),10-25.

Kienle A., \& Wessner M. (2005). Principles for cultivating scientific communities of practice. In P. v.d. Besselaar, G.d. Michelis, J. Preece, \& C. Simone (Eds.), Communities and Technologies 2005, Proceedings of the 2nd International conference on communities and technologies, Milano 2005. Berlin: Springer.

Kirby J., Hoadley C., \& Carr-Chellman A. (2005). Instructional design and the learning sciences: A citation analysis. Educational technology research and development, 53(1),37-48.

Koschmann T., Suthers D. D., Chan T.-W. (Eds.) (2005). Computer-supported collaborative learning (CSCL) 2005. Taipei, Taiwan: International Society of the Learning Sciences.

Lave J., \& Wenger E. (1991). Situated learning: Legitimate peripheral participation. Cambridge, University Press.

Newman M. E. J. (2004). Coauthorship networks and patterns of scientific collaboration. Proceeding of the National Academy of Science 101(Suppl 1), 5200-5205.

Nurmela K., Lehtinen E., \& Palonen T. (1999). Evaluating CSCL log files by social network analysis. In C.M. Hoadley, \& J. Roschelle (Eds.) Proceedings of the computer support for collaborative learning (CSCL) 1999 Conference (pp. 434-444). Lawrence Erlbaum Associates (LEA): Mahwah, NJ.

Nurmela K., Palonen T., Lehtinen E., \& Hakkarainen K. (2003). Developing tools for analyzing CSCL process. In B. Wasson, S. Ludvigsen, \& U. Hoppe (Eds.), Designing for change in networked learning environments. Proceedings of the international conference on computer support for collaborative learning 2003 (pp. 333-342). Dordrecht, The Netherlands: Kluwer.

O’Malley C. (1995). (Ed.). Computer-supported collaborative learning. Heidelberg: Springer.

Puntambekar S., \& Young M. F. (2003). Moving toward a theory of CSCL. In B. Wasson, S. Ludvigsen, \& U. Hoppe (Eds.), Designing for change in networked learning environments. Proceedings of the international conference on computer support for collaborative learning 2003 (pp. 503-512). Dordrecht, The Netherlands: Kluwer.

Reffay C., \& Chanier T. (2003). How social network analysis can help to measure cohesion in collaborative distance learning. In B. Wasson, S. Ludvigsen, \& U. Hoppe (Eds.), Designing for change in networked learning environments. Proceedings of the international conference on computer support for collaborative learning 2003 (pp. 343-352). Dordrecht, The Netherlands: Kluwer.

Schnase J. L., \& Cunnius E. L. (Eds.) (1995). Proceedings of the First international conference on computer support for collaborative learning (CSCL' 95). Mahwah, NJ: Lawrence Erlbaum Associates (LEA).

Scott J. (1991). Social network analysis: A handbook. London: SAGE Publications.

Small H. (1973). Co-citation in scientific literature-New Measure of Relationship between 2 Documents. Journal of the American Society for Information Science, 24(4):265-269. 
Stahl G. (Ed.) (2002a). Computer support for collaborative learning. Foundations for a CSCL 747 Community. Proceedings of the International Conference on Computer Support for Collabo- 748 rative learning 2002. Mahwah, NJ: Lawrence Erlbaum Associates (LEA).

Stahl G. (2002b). Contributions to a theoretical framework for CSCL. In G. Stahl (Ed.), Computer support for collaborative learning. Foundations for a CSCL community. Proceedings of the international conference on computer support for collaborative learning 2002 (pp. 62-71). Mahwah, NJ: Lawrence Erlbaum Associates (LEA).

Wasson B., Ludvigsen S., \& Hoppe U. (Eds.) (2003a). Designing for change in networked learning environments. Proceedings of the international conference on computer support for collaborative learning 2003. Dordrecht, The Netherlands: Kluwer.

Wasson B., Baggetun R., Hoppe U., \& Ludvigsen S. (Eds.) (2003b). CSCL 2003. Community events. Bergen, Norway: InterMedia, University of Bergen.

Wenger E., McDermott R., \& Snyder W. M. (2002). Cultivating communities of practice: A guide to 759 managing knowledge. Cambridge, MA: Harvard Business School Press.

White H. D., \& McCain K. W. (1998). Visualizing a discipline: An author co-citation analysis of information science, 1972-1995. Journal of the American Society for Information Science, 49(4):327-356.

Woodruff E. (1999). Concerning the cohesive nature of CSCL communities. In C. M. Hoadley \& J. Roschelle (Eds.), Proceedings of the computer support for collaborative learning (CSCL) 1999 conference (pp. 677-680). Mahwah, NJ: Lawrence Erlbaum Associates (LEA). 